\title{
Transit time indices derived from forced expiratory spirograms: repeatability and criteria for curve selection and truncation
}

\author{
D.J. Chinn*, J.E. Cotes
}

Transit time indices derived from forced expiratory spirograms: repeatability and criteria for curve selection and truncation. D.J. Chinn, J.E. Cotes. CERS Journals Ltd 1994. ABSTRACT: Transit time analysis applied to spirograms truncated with respect to volume, not time, could be informative in population surveys. The present paper asks the questions: How does averaging several forced expirations affect the within subject variability at different levels of truncation? If only one spirogram is analysed, how should it be chosen? Are the results likely to be influenced by prior bronchodilatation?

The subjects were 46 men, selected by stratified random sampling from a shipyard population. Spirograms were obtained in quintuplicate, on two occasions, an average of nine days apart. Using the three "best" spirograms, transit time indices were calculated from averaged moments and from single curves selected in eight different ways; the analyses were performed on complete expirations, and after truncation by volume at levels between $75-99 \%$ of forced vital capacity (FVC), and by time (at $6 \mathrm{~s})$.

Indices from averaged moments were found to be more reproducible and yielded higher intra-class correlations than indices from single curves. Of the latter, the curve selected as having the largest forced vital capacity also yielded acceptable results. Prior inhalation of a bronchodilator aerosol did not reduce the variability.

The averaging procedure is recommended for respiratory surveys of working men. For this application, the optimal level of truncation appeared to be by volume at $90 \%$ FVC, but on theoretical grounds truncation at 75 and $99 \%$ of $\mathrm{FVC}$ could also be informative.

Eur Respir J., 1994, 7, 402-408.
Respiration and Exercise Laboratory, Dept of Physiological Sciences, The University, Newcastle-upon-Tyne, UK. *City Hospital, Edinburgh.

Correspondence: J.E. Cotes Respiration and Exercise Laboratory Dept of Physiological Sciences Ridley Building

The University

Newcastle-upon-Tyne NE1 7RU

UK

Keywords: Forced expiration moments analysis repeatability spirometry standardization transit times

Received: November 181992 Accepted after revision July 191993
The dispersion of times required to expel gas molecules from the lungs during a forced expiration can be described by the mean transit time (MTT), its standard deviation (SDTT), moment ratio (MR) and index of skewness (IoSTT). These statistical descriptions are calculated using time to the power of 1,2 and 3 , in order to obtain the first three moments about the origin of the volume/time relationship [1]. The MTT is equal to the first moment, the SDTT and MR are calculated from the first two moments, and the IoSTT is derived from all three moments. Indices obtained by moments analysis have theoretical advantages over conventional flow and volume indices of airflow limitation, in that they: 1) describe the entire spirogram; 2) focus on prolongation of expiratory time; and 3) are relatively independent of lung size [2]. The analysis has the disadvantage that, in patients with airflow limitation, events occurring at the end of a forced expiration, are rather variable. The variability can be reduced by omitting from the analysis the last part of the expiration, thereby truncating the spirogram. Variability might also be reduced by prior bronchodilatation, or by averaging the results for several forced expirations.

In early studies, truncation was performed at $6 \mathrm{~s}$ from the start of expiration [3-5], but this led to the proportion of the expirate which was analysed varying between subjects to an unacceptable extent. Comparability between subjects can be achieved by truncating with respect to volume, rather than time. MiLLER and PinCOCK [6], in a well-documented study, recommended truncation at $90 \%$ forced vital capacity (FVC) for the moment ratio, and $75 \%$ FVC for the mean transit time. However, the latter leads to loss of information about the tail of the curve. The third moment and index of skewness were not analysed.

We previously investigated the selection and number of curves which should be included [7]. Based on the first three curves which met the criteria for acceptability of the European Coal and Steel Community [8], optimal reproducibility was observed for indices obtained using averaged moments, whilst the most reproducible single curve was that having the shortest mean transit time. The 
study had the following limitations: the definition of the start of expiration (zero time) did not conform to current recommendations $[8,9]$, the algorithm used to derive the averaged moments and hence the "mean" curve was suboptimal, and whilst truncation at $6 \mathrm{~s}$ was considered, that with respect to volume was limited to truncation at $99 \%$ FVC.

These deficiencies have been rectified in the present account, which extends the analysis of MILLER and PINCOCK [6] with respect to averaged moments, the volume at truncation, the index of skewness, and the additional use of a bronchodilator aerosol (which might be expected to reduce the variability of the indices). It is concluded that truncation at 90 and $99 \%$ of FVC is valid on statistical grounds, and that, where possible, indices should be derived from averaged moments rather than from a single curve.

\section{Methods}

\section{Subjects}

Subsequent to two epidemiological studies of lung function in shipyard workers, 48 men were identified, and gave their informed consent to further study. Twelve subjects were selected at random from a population of 240 apprentices who were taking part in a growth study, and 36 from a population of 346 established tradesmen. Subjects were selected by stratified random sampling, in order to provide a group balanced with respect to shipyard trade (welder or caulker burner compared with other trades) and to smoking category (nonsmoker, ex-smoker or smoker). In the event, of the 36 men selected, one man did not attend, and the results for another did not meet the criteria for acceptability (see below); thus, the results for 34 were included in the analysis. The measurements were made in a mobile laboratory, at the same time of day on two days (occasions), with an average of 9 days between (range 6-24 days). The observer (DJC) and the equipment were the same throughout.

\section{Spirometry}

Spirometry was undertaken using a McDermott digital spirometer, with storage and play-back facilities. The output from the spirometer was in the form of digital volume per $10 \mathrm{~ms}$ time increments. The data were stored on magnetic tape (Sony TC-525 cassette recorder). After each blow, the flow-volume curve was inscribed in delayed time on an XY-plotter (JJ Instruments). The spirometer's microprocessor computed and displayed the forced expiratory volume in one second $\left(\mathrm{FEV}_{1}\right), \mathrm{FVC}$, peak expiratory flow (based on 10 time increments) (PEF), and maximal flow when $50 \%$ and $25 \%$ remained to be expired $\left(\mathrm{MEF}_{50}\right.$ and $\mathrm{MEF}_{25}$, respectively). Volumes were expressed in litres body temperature and pressure, saturated (BTPS). Before each measurement session, the equipment was calibrated using a standard orifice and weight. The accuracy expressed in terms of the forced expiratory volume, was consistently better than $1 \%$; the resolution was $10 \mathrm{ml}$. On each occasion, the subject provided five blows, which met the criteria that FVC was within $5 \%$ of the maximum, the PEF was within $10 \%$ of the maximum, and the curves were of similar overall shape. Any additional curves were discarded. The interval between blows was approximately one minute. A noseclip was not used. Using the microprocessor, the start of the breath (time zero) was defined as the point when the first $100 \mathrm{ml}$ had been expired. The end of the breath was when the volume change in $2 \mathrm{~s}$ was less than $10 \mathrm{ml}$. The 34 tradesmen then inhaled two puffs of a bronchodilator aerosol (salbutamol, $0.2 \mathrm{mg}$ ), after which five further acceptable blows were recorded starting 15 min later. The same protocol was followed at both attendances.

The magnetic tape records were analysed subsequently, using a personal computer (Amstrad PC1640). The flow-volume and volume-time curves were delineated, and the indices were recalculated. They were then checked against those obtained at the time of the initial examination. These procedures ensured that the tape records were free from distortion. The start of the breath (time zero) was then redefined as the point where back extrapolation of the steepest part of the volume-time relationship intersected with zero volume. In practice, the $\mathrm{FEV}_{1}$ calculated by back extrapolation exceeded that based on the volume criterion by, on average, $0.1 \mathrm{l}$.

For each subject, on both occasions, the three curves with the largest FVC out of the five acceptable curves were selected for further analysis. The other curves were not considered further. If two curves had an identical FVC, then the curve with the larger FEV ${ }_{1}$ was accepted. The possibility that this procedure identified curves obtained using submaximal effort was excluded as in all cases the $\mathrm{FEV}_{1}$ was within $5 \%$ of the maximum recorded. The three selected curves were used to obtain both averaged moments and transit time indices for the curves having the largest values for the volume, flow and area indices.

The data from each blow were in the form of volume per $10 \mathrm{~ms}$ of expiratory time (that is, 100 data points for every second of forced expiration). Instantaneous flow throughout the forced expiration was derived, using a central mean formula encompassing 10 increments [10], and the flows and corresponding volumes were summated to yield the total area under the flow-volume curve (AREA F/V). Average flows over different fractions of the forced expiration were calculated via the corresponding forced expiratory times (FET). Thus, the FET after expiration of 25 and $75 \%$ of FVC were used to derive the maximal mid-expiratory flow (MMEF) $(\mathrm{MMEF}=0.5$ $\left.\mathrm{FVC} /\left(\mathrm{FET}_{75}-\mathrm{FET}_{25}\right)\right)$ and those after expiration of 75 and $85 \%$ of $\mathrm{FVC}$ to derive the $\mathrm{FEF}_{75-85}\left(\mathrm{FEF}_{75-85}=0.1 \mathrm{FVC} / \mathrm{FET}_{85}{ }^{-}\right.$ FET $\left._{75}\right)$ ).

The first three moments of the distribution of transit times were calculated at seven levels of truncation (75, $80,85,90,95,99$ and $100 \%$ of forced vital capacity), and at $6 \mathrm{~s}$ of expiration if this was less than FET at $100 \%$ FVC. The calculations are given in figure 1 . The moments were used to derive the MTT, SDTT, MR and IoSTT [1]. The coefficient of variation of transit times was not used, because the MR yields essentially the same information [7]. 


\section{Derivation of averaged moments}

Average moments were used to describe an "average curve". In the derivation, the average first moment ( $\overline{\mathrm{M} 1}$ or $\overline{\mathrm{MTT}}$ ) was the mean of the three results, thus:

$$
\overline{\mathrm{M}} 1=\left(\mathrm{M} 1_{\text {blow } 1}+\mathrm{M} 1_{\text {blow } 2}+\mathrm{M} 1_{\text {blow } 3}\right) / 3
$$

The average second moment ( $\overline{\mathrm{M} 2})$ was calculated by inserting into the standard equation (fig. 1) the value calculated for $\overline{\mathrm{M} 1}$, together with the "mean" standard deviation of transit times obtained by averaging the respective variances, thus:

$$
\overline{\mathrm{SDTT}}=\left(\left(\mathrm{SDTT}_{\text {blow } 1}^{2}+\mathrm{SDTT}_{\text {blow } 2}^{2}+\mathrm{SDTT}_{\text {blow } 3}^{2}\right) / 3\right)^{1 / 2}
$$

No allowance was made for the number of data points, because these were large (100 per second of expiration) and their inclusion made very little difference to the estimate obtained. The mean third moment ( $\overline{\mathrm{M} 3})$, likewise, was calculated from equations in figure 1, after first averaging the skewness from each curve $\left(=\sum\left(\right.\right.$ IoSTT $\left.\left.\times \mathrm{SDTT}^{3}\right) / 3\right)$, and then using estimates of $\overline{\mathrm{M} 1}$ and $\overline{\mathrm{M} 2}$, from above.

The transit time indices were derived from the averaged moments and from single curves selected in various ways: 1) by size, as the largest FVC, FEV $+F V C$, AREA F/V, or FET (designated as $>$ FVC etc.);

2) by the volume/time relationship, as the largest $\mathrm{FEV}_{1} \%$, shortest FET, or least MTT truncated at $99 \%$ FVC (designated, respectively, as $\left.>\mathrm{FEV}_{1} \%,<\mathrm{FET},<\mathrm{MTT}\right)$;

3 ) by flow rate as largest PEF (designated $>\mathrm{PEF}$ ).

\section{Statistics}

The relationship of the variance within a subject to that between subjects was described by the intra-class correla- tion coefficient [11], which was computed from a one-way analysis of variance on the log transformed data, pooled between occasions to provide six replicates per subject. The log transformation was necessary because the procedure reduced the skewness of the distribution for the majority of indices. The correlation coefficient was, in effect, a signal-to-noise ratio describing overall variability, with a high correlation implying a small variation within-subjects compared to that between-subjects.

Variability within a session and between occasions was expressed, using the repeatability coefficient of BLAND and Altman [12], which is the $95 \%$ range for the difference in two repeat measurements; thus, $95 \%$ of individuals will have a difference between two repeat measures equal to or less than the coefficient. The coefficient within a session was calculated from the pooled within-session standard deviation for the three selected blows; that between occasions was twice the standard deviation of the difference between occasions. For the majority of indices the between-occasion differences were normally distributed, as assessed by probability plots, and unrelated to the mean levels; the mean differences were close to zero. The repeatability coefficients had the same units as the indices to which they referred. To compare the repeatability of the different indices, the variability within-sessions was expressed in dimension-less units as the coefficient of variation $(\mathrm{CoV})$ $(\mathrm{CoV}=\mathrm{SD} \times 100 /$ mean $)$; a log transformation was not used, because for the majority of indices, the within-session standard deviation was proportional to the subject's mean. Variability between-occasions was expressed as ( $\mathrm{x} 1$ $\mathrm{x} 2) \times 100 /$ mean $(\Delta x / \bar{x} \%)$, ignoring the sign, where $\mathrm{x} 1$ and $\mathrm{x} 2$ were the values of the relevant index on the two occasions.

Differences between transit time indices derived using different procedures were assessed by paired t-test (twotailed), and a $5 \%$ probability was considered meaningful.
$10 \mathrm{~ms}$ increments (not to scale) from time $=0$ to time $=$ FET

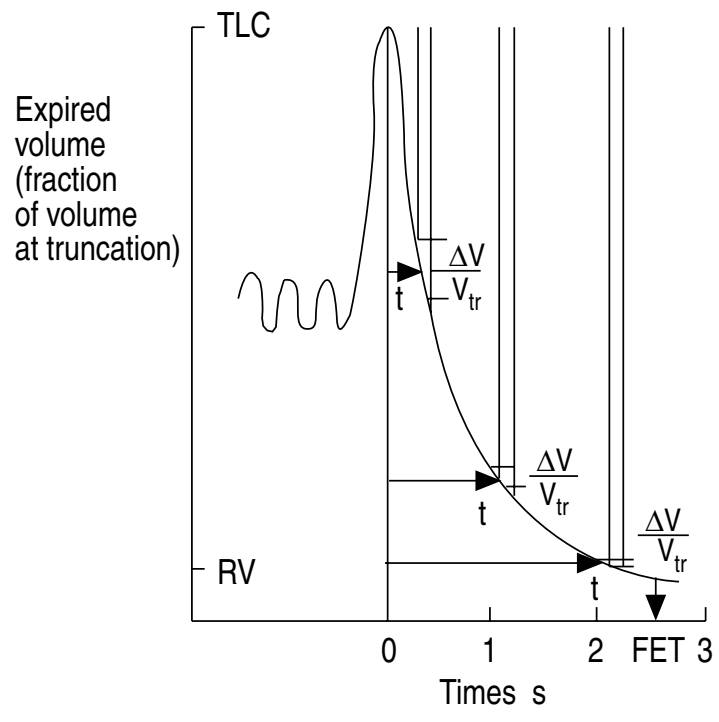

Moment analysis applied to the distribution of transit times yields the following:

First moment (M1)

Second moment (M2)

Third moment (M3)

Derived indices:

Moment ratio (MR)

$\begin{aligned} & \mathrm{t}=\mathrm{T}_{\mathrm{tr}} \\ & =\sum_{\mathrm{t}=\mathrm{O}}^{\mathrm{t}}\end{aligned} \quad \frac{\Delta \mathrm{V}}{\mathrm{V}_{\mathrm{tr}}} \times \mathrm{t} \quad \begin{array}{r}(=\text { mean transit } \\ \text { time, MTT })\end{array}$

$\underset{t=0}{t=T_{\text {tr }}} \quad \frac{\Delta \mathrm{V}}{\mathrm{V}_{\mathrm{tr}}} \times \mathrm{t}^{2}$

$\begin{aligned} & \mathrm{t}=\mathrm{T}_{\mathrm{tr}} \\ & \mathrm{t}=\mathrm{O}\end{aligned} \frac{\Delta \mathrm{V}}{\mathrm{V}_{\mathrm{tr}}} \times \mathrm{t}^{3}$

Standard deviation (SDTT)

$=\frac{\sqrt{\mathrm{M} 2}}{\mathrm{M} 1}$

Coefficient of variation (CoVTT)

$=\sqrt{M 2-(M 1)^{2}}$

$=\frac{\text { SDTT }}{\text { MTT }}$

Index of skewness (IoSTT)

$$
=\frac{M 3-3(M 1 M 2)+2(M 1)^{3}}{(S D T T)^{3}}
$$

Fig. 1. - Derivation of transit time indices based on a volume-time curve obtained during forced expiration from total lung capacity. FET: forced expiratory time=time to expire $99 \% \mathrm{FVC}$; $\mathrm{t}$ : transit times; $\mathrm{V}_{\mathrm{tr}}$ : volume at truncation, e.g. $75 \% \mathrm{VC}, 90 \% \mathrm{VC}, 99 \% \mathrm{VC}$; $\mathrm{T}_{\mathrm{tr}}$ : time at truncation; TLC: total lung capacity; RV: residual volume. 
The analysis was carried out on the University of Newcastle upon Tyne's mainframe computer (Amdahl), using the Statistical Package for Social Sciences (SPSS ${ }^{x}$ ). Reference values used for the interpretation of some results were, for indices of ventilatory capacity, those of Cotes[13], and for transit time indices, those of MILLER and co-workers [14].

\section{Results}

\section{Subjects}

The 46 men were aged 21-45 (mean 33) yrs; of these 14 were smokers and 29 were occupationally exposed to fumes from welding or burning mild steel. Most of the subjects were asymptomatic, 22 experienced occasional wheeze and 8 had chronic bronchitis, defined as phlegm production on most days for as much as three months each year. None were asthmatic or in receipt of treatment for chest disease. The mean levels of the flow and volume indices (table 1) were typical of healthy men, as was MR at 90\% FVC. However, in two men FEV, was more than 2 SD below predicted, and in 12 men the moment ratio at $100 \% \mathrm{FVC}$ was increased above $2 \mathrm{SD}$. In three men the MTT at one or more levels of truncation was abnormal. The average increase in $\mathrm{FEV}_{1}$ after salbutamol was $3.3 \%$ (range -1.3 to $10.9 \%$ ).

Intra-class correlation and repeatability of flow and volume indices

Of the flow and volume indices, the FVC and $\mathrm{FEV}_{1}$ were highly reproducible and exhibited high intra-class correlations. The flow rates recorded at the tail of the flow-volume curve scored relatively badly in these respects, whilst $\mathrm{FEV}_{1} \%$, AREA F/V and flows recorded over the middle of the FVC manoeuvre $\left(\mathrm{MMEF}\right.$ and $\mathrm{MEF}_{50}$ ) were intermediate (table 1).
Intra-class correlation and repeatability of FET and transit time indices

Intra-class correlations and within-session variability. For all the indices, the variability within subjects as a proportion of that between subjects was in general very small, especially at truncation volumes in the range $75-90 \%$ of FVC. The variability increased (i.e. the intra-class correlation coefficients decreased) as the volume at truncation approached FVC (fig. 2). This result was independent of whether or not a bronchodilator aerosol had been inhaled. The within-session variability exhibited a similar pattern, with the variability associated with the level of truncation rising steeply towards the tail of the spirogram (fig. 3). Truncation at $99 \%$ FVC usefully reduced the variability, compared with using the complete expiration. Truncation at $6 \mathrm{~s}$ yielded a relatively variable result, similar to truncating at near to full expiration.

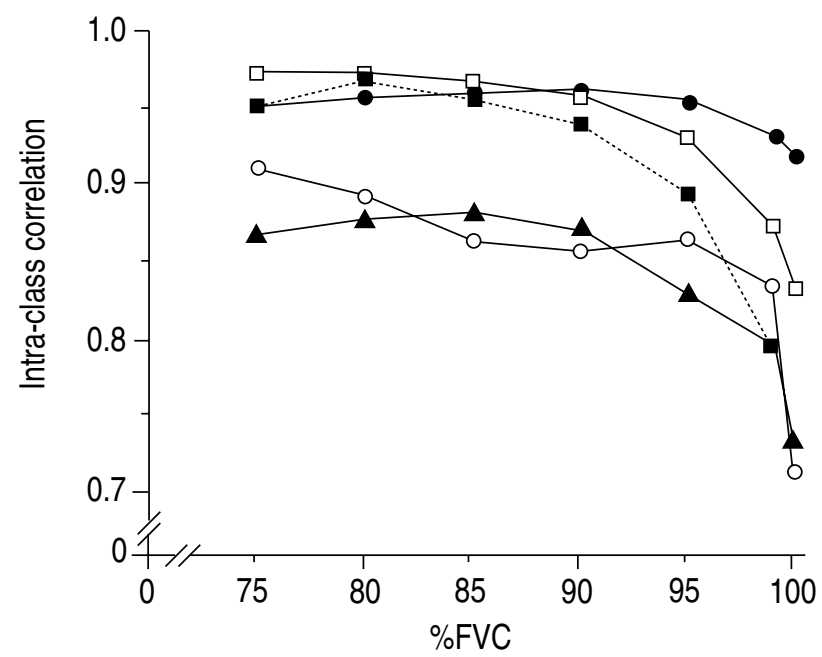

Fig. 2. - Relationship of intra-class correlation to volume at truncation (\%FVC) for FET, MTT and derived indices (n=46). - - : MTT; - - : SDTT; -...: FET; —-HoSTT; -AMR. MTT: mean transit time; SDTT: standard deviation of mean transit time; FET: forced expiratory time; IoSTT; index of skewness of transit time. For further abbreviations see legend to figure 1 .

Table 1. - Repeatability of flow and volume indices ${ }^{\dagger}$

\begin{tabular}{|c|c|c|c|c|c|c|}
\hline \multirow[t]{2}{*}{ Index } & \multirow[t]{2}{*}{$\begin{array}{l}\text { Overall } \\
\text { mean }\end{array}$} & \multirow[t]{2}{*}{$\begin{array}{l}\text { Intra-class } \\
\text { correlation }\end{array}$} & \multicolumn{2}{|c|}{$\begin{array}{c}\text { Repeatability } \\
\text { coefficient }\end{array}$} & \multicolumn{2}{|c|}{ Variability } \\
\hline & & & $\begin{array}{l}\text { Within- } \\
\text { session* }\end{array}$ & $\begin{array}{l}\text { Between- } \\
\text { occasion }\end{array}$ & $\begin{array}{l}\text { Within- } \\
\text { session* } \\
(\mathrm{CoV}, \%)\end{array}$ & $\begin{array}{l}\text { Between- } \\
\text { occasion } \\
(\Delta \mathrm{x} / \overline{\mathrm{x}}, \%)\end{array}$ \\
\hline FVC $l$ & 5.12 & 0.980 & 0.129 & 0.282 & 0.9 & 2.2 \\
\hline $\mathrm{FEV}_{1} l$ & 4.06 & 0.979 & 0.125 & 0.238 & 1.1 & 2.3 \\
\hline $\mathrm{FEV}_{1}^{1} \%$ & 80 & 0.969 & 2.4 & 3.2 & 1.1 & 1.7 \\
\hline $\operatorname{PEF} l \cdot \mathrm{s}^{-1}$ & 10.12 & 0.924 & 0.65 & 1.22 & 2.3 & 4.8 \\
\hline $\mathrm{MEF}_{50} \quad l \cdot \mathrm{s}^{-1}$ & 4.77 & 0.960 & 0.50 & 0.75 & 4.0 & 6.2 \\
\hline $\mathrm{MEF}_{25} \quad l \cdot \mathrm{s}^{-1}$ & 1.86 & 0.921 & 0.39 & 0.48 & 8.4 & 10.8 \\
\hline MMEF $\quad l \cdot \mathrm{s}^{-1}$ & 3.98 & 0.969 & 0.36 & 0.57 & 3.4 & 5.9 \\
\hline $\mathrm{FEF}_{75-85} l \cdot \mathrm{s}^{-1}$ & 1.27 & 0.929 & 0.24 & 0.29 & 7.6 & 9.6 \\
\hline AREA $\mathrm{F} / \mathrm{V} \quad l^{2} \cdot \mathrm{s}^{-1}$ & 22.21 & 0.968 & 1.68 & 2.90 & 2.7 & 5.8 \\
\hline
\end{tabular}

: the indices which are used are those described in the text; *: first day only, results of second day were not statistically different; CoV: coefficient of variation; FVC: forced vital capacity; $\mathrm{FEV}_{1}$ : forced expiratory volume in one second; PEF: peak expiratory flow; $\mathrm{MEF}_{50}$ and $\mathrm{MEF}_{25}$ : maximal expiratory flow when $50 \%$ and $25 \%$, respectively, remained to be expired; MMEF: maximal mid-expiratory flow; $\mathrm{FEF}_{75-85}$ : forced expiratory flow at $75-85 \%$ FVC: AREA F/V: total area under the flow-volume curve. $*$ see methods. 


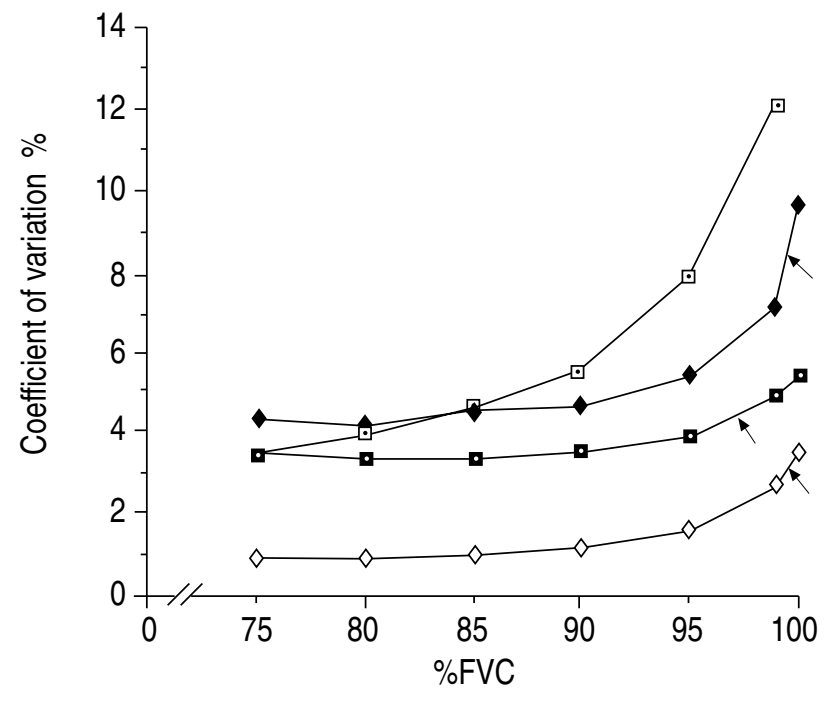

Fig. 3. - Effects of level of truncation upon the within-session coefficient of variation. Between 75 and $85 \%$ truncation the curves were nearly horizontal. The arrows indicate the effects of truncation at $6 \mathrm{~s} . \longrightarrow$ : FET; $\longrightarrow$ IoSTT; $\longrightarrow:$ MTT; $\multimap-:$ MR. For abbreviations see legends to figures 1 and 2 .
Between-occasion variability: effects of criterion used to select the data. Transit time indices were calculated from averaged moments, and from moments taken from single curves selected as having certain features (see Methods). Different selection criteria frequently identified the same curve in a set of three. For example, the curve having the largest AREA F/V, largest $\mathrm{FVC}$ and largest $\mathrm{FEV}_{1}+\mathrm{FVC}$ frequently identified the same curve, as did the criteria largest $\mathrm{FEV}_{1} \%$ and smallest FET, FVC and $\mathrm{MTT}_{99 \% \mathrm{FVC}}$.

The effect of the selection criteria on the mean values of the transit time indices was examined by comparing the results using average moments with those for the single curve with the lowest MTT, the highest FVC and the highest $\mathrm{FEV}_{1}+\mathrm{FVC}$. The results of the comparisons were consistent at all levels of truncation by volume (table 2 ).

The mean values using average moments and using the criterion $>\mathrm{FEV}_{1}+\mathrm{FVC}$ were similar, as were those for $>\mathrm{FVC}$, except in the case of the derived MTT, which was higher by $1-2 \%$ depending on the level of truncation. Using the criterion $<$ MTT, the mean values were significantly lower than those based on the other criteria in all but one instance; the reductions were in the range $2-5 \%$, depending on which selection criterion and which index was under consideration.

Table 2. - Overall mean values and between-occasion repeatability coefficients (Rep coeff) and variability $(\Delta x / \mathbb{x})$ for transit time indices derived from average moments and selected single curves truncated at 99,90 and $75 \%$ of FVC

\begin{tabular}{|c|c|c|c|c|c|}
\hline Derivation & & $\begin{array}{l}\text { Average } \\
\text { moments }\end{array}$ & $<\mathrm{MTT}$ & $>\mathrm{FVC}$ & $>\mathrm{FEV}_{1}+\mathrm{FVC}$ \\
\hline \multicolumn{6}{|c|}{ Truncation at $99 \%$ FVC } \\
\hline \multirow[t]{3}{*}{ MTT s } & Mean & 0.712 & $0.678^{*}$ & $0.724 *$ & 0.715 \\
\hline & Rep coeff & 0.154 & 0.164 & 0.154 & 0.178 \\
\hline & $\Delta \mathrm{x} / \overline{\mathrm{x}} \quad \%$ & 7.0 & 7.8 & 8.0 & $8.8^{*}$ \\
\hline \multirow[t]{3}{*}{ MR } & Mean & 1.650 & $1.618 *$ & 1.654 & 1.654 \\
\hline & Rep coeff & 0.198 & 0.260 & 0.224 & 0.240 \\
\hline & $\Delta \mathrm{x} / \overline{\mathrm{x}} \%$ & 4.2 & 5.0 & 4.8 & 5.2 \\
\hline \multirow[t]{3}{*}{ SDTT $\mathrm{s}$} & Mean & 0.940 & $0.869 *$ & $0.959 *$ & 0.951 \\
\hline & Rep coeff & 0.368 & 0.404 & 0.380 & 0.414 \\
\hline & $\Delta \mathrm{x} / \overline{\mathrm{x}} \%$ & 11.9 & 14.0 & 13.7 & $15.1^{*}$ \\
\hline \multirow[t]{3}{*}{ IoSTT } & Mean & 2.598 & $2.449 *$ & 2.566 & 2.574 \\
\hline & Rep coeff & 0.718 & 1.108 & 0.850 & 1.108 \\
\hline & $\Delta \mathrm{x} / \overline{\mathrm{x}} \%$ & 9.6 & 12.8 & $12.1^{*}$ & $13.4 *$ \\
\hline \multicolumn{6}{|c|}{ Truncation at $90 \%$ FVC } \\
\hline \multirow[t]{3}{*}{ MTT s } & Mean & 0.467 & $0.452 *$ & $0.473 *$ & 0.466 \\
\hline & Rep coeff & 0.068 & 0.076 & 0.072 & 0.082 \\
\hline & $\Delta \mathrm{x} / \overline{\mathrm{x}} \%$ & 5.0 & $6.2 *$ & 6.1 & $6.6 *$ \\
\hline \multirow[t]{3}{*}{ MR } & Mean & 1.354 & $1.347 *$ & 1.352 & 1.353 \\
\hline & Rep coeff & 0.060 & 0.064 & 0.058 & 0.062 \\
\hline & $\Delta \mathrm{x} / \overline{\mathrm{x}} \%$ & 1.7 & 1.7 & 1.6 & 1.6 \\
\hline \multirow[t]{3}{*}{ SDTT $\mathrm{s}$} & Mean & 0.433 & $0.414 *$ & 0.436 & 0.431 \\
\hline & Rep coeff & 0.102 & 0.100 & 0.090 & 0.102 \\
\hline & $\Delta \mathrm{x} / \overline{\mathrm{x}} \%$ & 6.8 & 7.5 & 6.9 & 7.6 \\
\hline \multirow[t]{3}{*}{ IoSTT } & Mean & 1.279 & $1.228 *$ & 1.277 & 1.273 \\
\hline & Rep coeff & 0.274 & 0.264 & 0.322 & 0.312 \\
\hline & $\Delta \mathrm{x} / \overline{\mathrm{x}} \quad \%$ & 7.6 & 8.0 & $9.5^{*}$ & 9.1 \\
\hline \multicolumn{6}{|c|}{ Truncation at $75 \%$ FVC } \\
\hline \multirow{3}{*}{ MTT $\mathrm{s}$} & Mean & 0.306 & $0.298 *$ & $0.310 *$ & 0.306 \\
\hline & Rep coeff & 0.038 & 0.048 & 0.048 & 0.054 \\
\hline & $\Delta \mathrm{x} / \overline{\mathrm{x}} \quad \%$ & 5.0 & $6.5 *$ & 6.2 & $6.9^{*}$ \\
\hline \multirow[t]{3}{*}{ MR } & Mean & 1.242 & 1.242 & 1.240 & 1.241 \\
\hline & Rep coeff & 0.040 & 0.048 & 0.048 & 0.052 \\
\hline & $\Delta \mathrm{x} / \overline{\mathrm{x}} \%$ & 1.2 & $1.5^{*}$ & 1.5 & $1.6^{*}$ \\
\hline \multirow[t]{3}{*}{ SDTT $\mathrm{s}$} & Mean & 0.228 & $0.222 *$ & 0.230 & 0.227 \\
\hline & Rep coeff & 0.032 & 0.040 & 0.032 & 0.044 \\
\hline & $\Delta \mathrm{x} / \overline{\mathrm{x}} \quad \%$ & 5.4 & 6.1 & 5.6 & 6.2 \\
\hline \multirow{3}{*}{ IoSTT } & Mean & 0.692 & $0.675^{*}$ & 0.689 & $0.685^{*}$ \\
\hline & Rep coeff & 0.108 & 0.140 & 0.122 & 0.126 \\
\hline & $\Delta \mathrm{x} / \overline{\mathrm{x}} \%$ & 6.7 & $9.1 *$ & 8.0 & 7.8 \\
\hline
\end{tabular}

*: significant difference from average moments $(\mathrm{p}<0.05)$. For further abbreviations see legends to table 1 and fig. 2. 
The reproducibility between-occasions, expressed as $\Delta x / x \%$, was almost always better when calculated from the averaged moments than from single curves. The variability increased with the complexity of the index, being least for the moment ratio and greatest for IoSTT, with the MTT and SDTT intermediate. The variability also increased with the level of truncation by volume; this association was consistent for indices derived using averaged moments or the criterion $>$ FVC. In the case of MTT and IoSTT it was less consistent using the criterion $<$ MTT (table 2)

For indices derived from a single curve, the criterion used for selecting the curve influenced both the mean level and the reproducibility. The reproducibility was worst using the criterion $>\mathrm{PEF}$, and above average for the criteria $<\mathrm{MTT},>\mathrm{FVC}$ and $>\mathrm{FEV}_{1}+\mathrm{FVC}$. Considering these criteria at three levels of truncation (table 2) the criterion $>$ FVC gave the best reproducibility in all but three instances (MTT at $99 \%$ truncation using the criterion $<$ MTT, and IoSTT at 90 and $75 \%$ truncation using the criterion $<\mathrm{MTT}$ and $>\mathrm{FEV}_{1}+\mathrm{FVC}$, respectively).

\section{Discussion}

Transit time analysis is a way of describing events near the end of expiration, where the variability of the data is at its greatest $[15,16]$. The present analysis explores this part of the volume-time curve, and includes indices based on the higher moments, which were not considered by MiLler and PinCock [6]. The subjects were a sample from an industrial population, and the quality of the measurements met current standards for accuracy and reproducibility $[6,17,18]$. Thus, the results, which were independent of labile airflow limitation, might be expected to apply to occupational respiratory surveys. The relevance of the indices for this application was assessed after the manner of MiLLER and PINCOCK [6], who used the ratio of the variance for all the subjects relative to the within-day variability (equivalent to the intra-class correlation). However, this criterion should be interpreted with caution, since amongst the present shipyard population the peak expiratory flow proved to be a sensitive guide to the relative effects of smoking and welding fumes (unpublished observations), and yet, in the subsample the intra-class correlation was no better than 0.924 . Accordingly, the within-session and between-occasion variability have also been considered.

Method for averaging curves. The present comparisons were with respect to indices calculated from a hypothetical curve described by the average moments for the three "best" blows from the first five which were technically satisfactory. The averaged indices met the criteria that they had better within-session and between-occasion reproducibilities than those calculated from individual curves. The models used for deriving the $\overline{\text { MTT, SDTT }}$ and second moments ( $\overline{\mathrm{M} 2}$ ) were unambiguous, but several models were available for obtaining the average IoSTT and third moment (M3). Of these, three were rejected as being mathematically unsound, namely:
1) averaging the individual $\mathrm{M} 3$ values directly;

2) averaging the cube root of M3 from each curve, and then taking the cube of the value so obtained;

3) averaging the IoSTT values directly, and then using this together with $\overline{\mathrm{M} 1}$ and $\overline{\mathrm{M}} 2$ to obtain $\overline{\mathrm{M}} 3$.

Instead, $\overline{\mathrm{M} 3}$ was calculated by averaging the skewness and then working backwards (see Methods). This model appeared to be conceptually very nearly correct. For purposes of standardization, the alternative of selecting the optimal values from any of the three "best" curves, as has been recommended for flow-volume indices [9], was not available, as it could lead to the indices not being internally consistent.

Criteria for a single curve. The effects of basing the results on a single curve, instead of on average moments, were broadly similar at all levels of truncation. The agreement between the two approaches was closest using the criterion $>\mathrm{FEV}_{1}+\mathrm{FVC}$. However, the reproducibility between-sessions of the latter indices was relatively poor. The criterion $>$ FVC yielded indices which had the best reproducibility of any of the single curve indices, and most of them agreed quite well with those from average moments. For IoSTT the reproducibility was significantly worse than when using average moments, but despite this disadvantage, if transit time indices were to be obtained from a single curve it should probably be based on the criterion $>\mathrm{FVC}$, which is itself very reproducible between occasions (table 1). This conclusion differs from that of our previous analysis [7], when the criterion $<$ MTT was considered preferable. But, in that study, the models used for averaging were in some respects suboptimal (see introduction). Transit time analysis is best undertaken using a computer, in which case average moments can be calculated. If computer facilities are limited, the analysis should be applied to the curve having the largest FVC, provided that criteria for acceptability are met to ensure that the blow was achieved by maximal effort.

Level of truncation. The present findings suggest that for most of the indices the variability was fairly constant between the 75 and $95 \%$ levels of truncation (fig. 2). By contrast, previous workers [6] reported a linear decline, though in other respects their results were similar. One possible cause for the difference is that the present subjects were men, whereas, Miller and PINCOCK included women, whose $\mathrm{FEV}_{1} \%$, on average is higher. The effects of this bimodal distribution might be expected to extend to MTT and related indices, since MTT and $\mathrm{FEV}_{1} \%$ are highly correlated.

If confirmed, the present results would justify moving the recommended level of truncation for MTT from the $75 \%$ of forced vital capacity of MiLLER and PINCOCK [6], which yields reproducible results but is far from the end of expiration, to $90 \%$ or a higher level of truncation, where the effects of mild airflow limitation might be more apparent. The point of optimal truncation could even be at $99 \%$, where the reproducibility of some indices, though less than at lower levels of truncation, is both comparable with that of PEF (table 1) and much better than at $100 \%$. Thus, before a decision is made as to which level 
should be used routinely in respiratory surveys of working men, all three levels should be assessed for their relative usefulness; depending on the findings, a similar study of women might then be appropriate.

Acknowledgements: The authors are indebted to British Shipbuilders, to the men who participated, to the Medical Research Council, European Coal and Steel Community and the Wellcome Trust for financial support. Also, to R. Scott and E. Thompson of the University Department of Medical Physics for help with programming and to J. Matthews and other members of staff of the University Department of Medical Statistics for their advice.

\section{References}

1. Neuberger N, Levison H, Bryan AC, Kruger K. Transit time analysis of the forced expiratory spirogram in growth. J Appl Physiol 1976; 40: 329-332.

2. Permutt S, Menkes HA. Spirometry. Analysis of forced expiration within the time domain. In: Macklem PT, Permutt S, eds. Lung Biology in Health and Disease. Vol 12. The lung in the transition between health and disease. New York, Dekker, 1979; pp. 113-152.

3. Tockman M, Menkes H, Cohen B, et al. A comparison of pulmonary function in male smokers and nonsmokers. Am Rev Respir Dis 1976; 114: 711-722.

4. Macfie AE, Harris EA, Whitlock RML. Transit time analysis of the forced spirogram in healthy children and adults. J Appl Physiol 1979; 46: 263-267.

5. Liang A, Macfie AE, Harris EA, Whitlock RML. Transit time analysis of the forced expiratory spirogram during clinical remission in juvenile asthma. Thorax 1979; 34 : 194-199.

6. Miller MR, Pincock AC. Repeatability of the moments of the truncated forced expiratory spirogram. Thorax 1982; 37: 205-211.
7. Chinn DJ, Cotes JE. Transit time analysis of spirograms: which blow is best? Bull Eur Physiopathol Respir 1986; 22: 461-466.

8. Quanjer PhH, Tammeling GJ, Cotes JE, Pedersen OF, Peslin R, Yernault J-C. Standardised lung function testing 1993 Update. Eur Respir J 1993; 6 (Suppl. 16): 4-40.

9. American Thoracic Society. Standardization of spirometry 1987 update. Am Rev Respir Dis 1987; 136: 1285-1298.

10. McDermott M, McDermott TJ. Digital incremental techniques applied to spirometry. Proc R Soc Med 1977; 70: 169-171.

11. Chinn S. The assessment of methods of measurement. Stat Med 1990; 9: 351-362.

12. Bland JM, Altman DG. Statistical methods for assessing agreement between two methods of clinical measurement. Lancet 1986; i: 307-310.

13. Cotes JE. In: Lung Function: Assessment and Application in Medicine. 5th edn. Oxford, Blackwell, 1993.

14. Miller MR, Grove DM, Pincock AC. Time domain spirogram indices. Their variability and reference values in nonsmokers. Am Rev Respir Dis 1985; 132: 1041-1048.

15. Osmanliev DP, Davies EE, Pride NB. Transit time analysis of the forced expiratory spirogram in male smokers. Bull Eur Physiopathol Respir 1984; 20: 285293.

16. Miller MR, Pincock AC, Grove DM. Patterns of spirogram abnormality in individual smokers. Am Rev Respir Dis 1985; 132: 1034-1040.

17. Nickerson BG, Lemen RJ, Gerdes CB, Wegmann MJ, Robertson G. Within subject variability and percent change for significance of spirometry in normal subjects and in patients with cystic fibrosis. Am Rev Respir Dis 1980; 122: 859-866.

18. Partridge MR, Watson AC, Saunders KB. Moment analysis of the flow-time curve after breathing gases of different densities. Thorax 1981; 36: 38-44. 